\title{
Henoch-Schoenlein Purpura Following Severe Acute Respiratory Syndrome Coronavirus-2 Infection: A Case Report
}

\author{
Saeed Soleiman-Meigooni (i) ${ }^{1,}{ }^{*}$, Ramin Yaghmayee ${ }^{2}$, Ramin Hamidi-Farahani (iD ${ }^{3}$, Mousa Ahmadi ${ }^{3}$, \\ Allahyar Taheri ${ }^{4}$, Ali Asgari (ib ${ }^{3}$ and Azam Soleimani Najafabadi ${ }^{5}$ \\ ${ }^{1}$ Infectious Diseases Research Center, AJA University of Medical Sciences, Tehran, Iran \\ ${ }^{2}$ Department of Pathology, Khanevadeh Military Hospital, Tehran, Iran \\ ${ }^{3}$ Department of Infectious Diseases, Faculty of Medicine, AJA University of Medical Sciences, Tehran, Iran \\ ${ }^{4}$ Department of Dermatology, Faculty of Medicine, AJA University of Medical Sciences, Tehran, Iran \\ ${ }^{5}$ Department of Nephrology, Khanevadeh University Hospital, Tehran, Iran \\ "Corresponding author: Infectious Diseases Research Center, AJA University of Medical Sciences, Tehran, Iran Email: dr.saeed.meigooni@gmail.com
}

Received 2021 May 18; Accepted 2021 June 13.

\begin{abstract}
Introduction: As the novel coronavirus pandemic continues to affect people worldwide, immune-mediated inflammatory syndromes related to this virus have been reported. SARS Coronavirus-2 infection disease (COVID-19) may accompany various cutaneous symptoms, such as viral exanthems or wheels. These symptoms may occur at the early course of the disease or after that. Cutaneous symptoms of COVID-19 usually have a favorable outcome.

Case Presentation: We presented a rare case of inpatient COVID-19 pneumonia, who developed a purpuric rash, abdominal pain, and hematuria. His dermal histopathological study revealed small-vessel vasculitis. We diagnosed Henoch-Schoenlein purpura based on clinical and histopathological findings and treated him with intravenous dexamethasone followed by oral prednisolone. The purpuric rashes disappeared in two weeks.

Conclusions: Cutaneous manifestation of COVID-19 is usually diffuse maculopapular rashes. Other presentations include vesicular rashes and acral cyanosis. Dermal histopathological study in most patients with COVID-19 who developed cutaneous symptoms revealed perivascular inflammation and microthrombus in some cases. Thus, COVID-19 should be considered in any patient with a new onset of cutaneous symptoms.
\end{abstract}

Keywords: Henoch-Schoenlein Purpura, COVID-19, SARS Coronavirus-2

\section{Introduction}

By the end of 2020, more than 83 million confirmed cases of Coronavirus infection (COVID-19) and 1.8 million deaths occurred worldwide (1). Several studies reported the correlation between COVID-19 and inflammatory syndromes, such as Guillain-Barre, myocarditis, and encephalitis (2-4). Indeed, a significant proportion of mortalities and morbidities in COVID-19 is due to nonpulmonary immune-mediated complications. These syndromes may affect any organ and play an essential role in tissue damage and death (5). The cutaneous symptom is a relatively common presentation in COVID-19. It may occur at the onset of this disease or a few days later and usually have a favorable outcome. We reported a rare case of COVID-19 pneumonia who developed Henoch-Schoenlein purpura (HSP) on admission.

\section{Case Presentation}

The patient was a 21-old-year male referred to the emergency department with three days of fever, myalgia, shortness of breath, and dry cough, five days after close contact with a patient with COVID-19. He also complained of abdominal pain and hematuria for two days. Physical examination revealed a blood pressure of $92 / 55 \mathrm{mmHg}$, a pulse rate of 128 beats per minute, a respiratory rate of 28 per minute, an oral temperature of $38.6^{\circ} \mathrm{C}$, and $\mathrm{O} 2$ saturation of $88 \%$. He also had crackle in both lungs and a mild diffuse abdominal tenderness. The pulmonary computed tomography scan showed diffusely scattered ground-glass opacities. The lab tests showed a white cell count of 5300 per cubic millimeter (consisting of $83 \%$ of polymorphonuclears, $13 \%$ lymphocytes, and $4 \%$ monocytes), a hemoglobin level of $11.4 \mathrm{mg} / \mathrm{dL}$, a platelet count of 314,000 per cubic 
millimeter, and a creatinine level of $1.1 \mathrm{mg} / \mathrm{dL}$. The firsthour erythrocyte sedimentation rate level was 89 , and the C-reactive protein level was $68 \mathrm{mg}$ per liter. Urine analysis showed mild proteinuria and 20 - 25 red blood cells in a 40x magnification field with $30 \%$ dysmorphic. The nasopharyngeal swab for the SARS Coronavirus-2 polymerase chain reaction (PCR) was positive.

We started treatment with parenteral ceftriaxone and pantoprazole, oral azithromycin and lopinavir/ritonavir, and oxygen supplement. The pulmonary symptoms recovered gradually during the following days, but abdominal pain and malaise continued. We also asked for a nephrology consultation and complete abdominopelvic ultrasound for evaluating hematuria. The ultrasound study was unremarkable. Other laboratory tests showed a urine protein level of $565 \mathrm{mg}$ in a day, negative results for the urine culture, anti-nuclear antibody, anti-doublestranded DNA, antineutrophil cytoplasmic antibodies, HBs antigen, HCV antibody, and HIV antibody. Also, D-Dimer, prothrombin and partial thromboplastin times, peripheral blood smear, and the serum complements were normal. In the second week of admission, a palpable purpuric rash appeared on his back and lower extremities and extended in two days (Figure 1). Upon consultation with a dermatologist and rheumatologist, we performed a skin punch biopsy and started intravenous dexamethasone 4 mg three times a day, which improved his condition in the following days. The histopathology study revealed superficial lymphocytic infiltrate and small-vessel vasculitis in the dermis (Figure 2). We diagnosed HSP based on clinical presentations and histopathological findings. Finally, we discharged him on day 18 of admission without any vital organs damage with oral prednisolone and ferrous sulfate supplement. The purpuric rashes disappeared after two weeks.
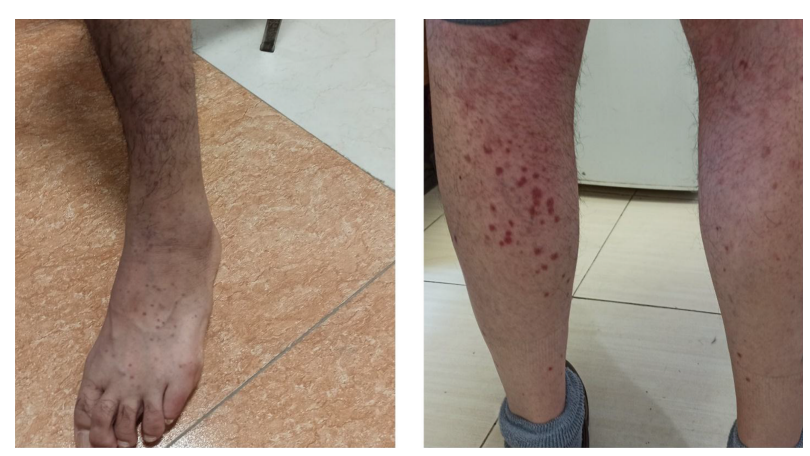

Figure 1. The palpable purpuric rash appeared on the back and lower extremities on the second week of admission
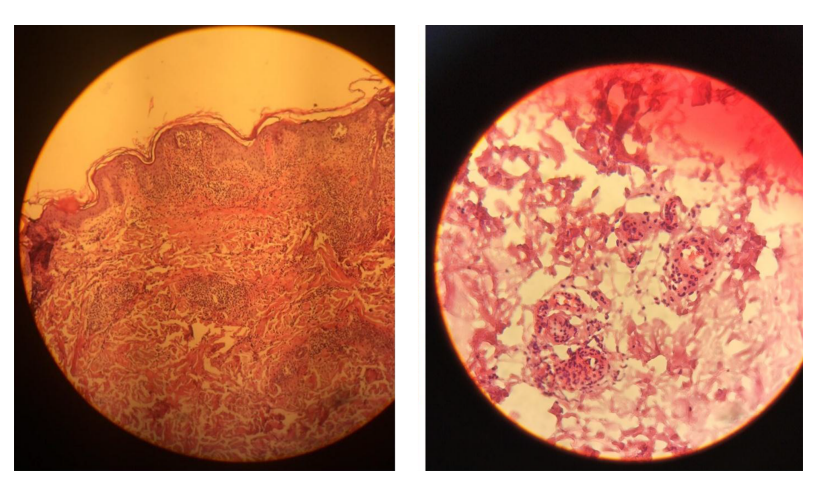

Figure 2. Superficial lymphocytic infiltrate and small-vessel vasculitis in the histopathological study of the dermis

\section{Discussion}

Henoch-Schoenlein purpura is a small-vessel vasculitis, which mainly affects the skin and mucous membranes. It may develop after upper respiratory tract infections such as Streptococci, Adenoviruses, and coxsackievirus (6). In our case, HSP occurred after SARS Coronavirus-2 infection, which is a new manifestation of COVID-19. The cutaneous presentation of COVID-19 is often like the other viral exanthemas, such as maculopapular rash. Table 1 lists the different types of dermal histopathology in COVID-19. As we showed in the table, the most common cutaneous manifestations of COVID-19 are widespread maculopapular rashes, papulovesicular rashes, and acral cyanosis. Skin symptoms in COVID-19 are usually self-limited and leave with a favorable outcome, but severe dermal involvement such as vasculitis needs a systemic treatment. Physicians should consider COVID-19 in the differential diagnosis of a new-onset cutaneous symptom, even a rare dermal presentation such as vasculitis.

\section{Footnotes}

Authors' Contribution: Saeed Soleiman-Meigooni as the main physician, wrote the primary and final draft. Ramin Yaghmaee as the pathologist, diagnosed vasculitis and reviewed the literature. Ramin Hamidi-Farahani reviewed the literature and contributed to the treatment. Ali Asgari reviewed the literature and contributed to the treatment. Moosa Ahmadi reviewed the literature and contributed to the treatment. Allahyar Taheri as the dermatologist, contributed to diagnosis and literature review. Azam Soleimani, as the nephrologist, contributed to diagnosis and literature review. 


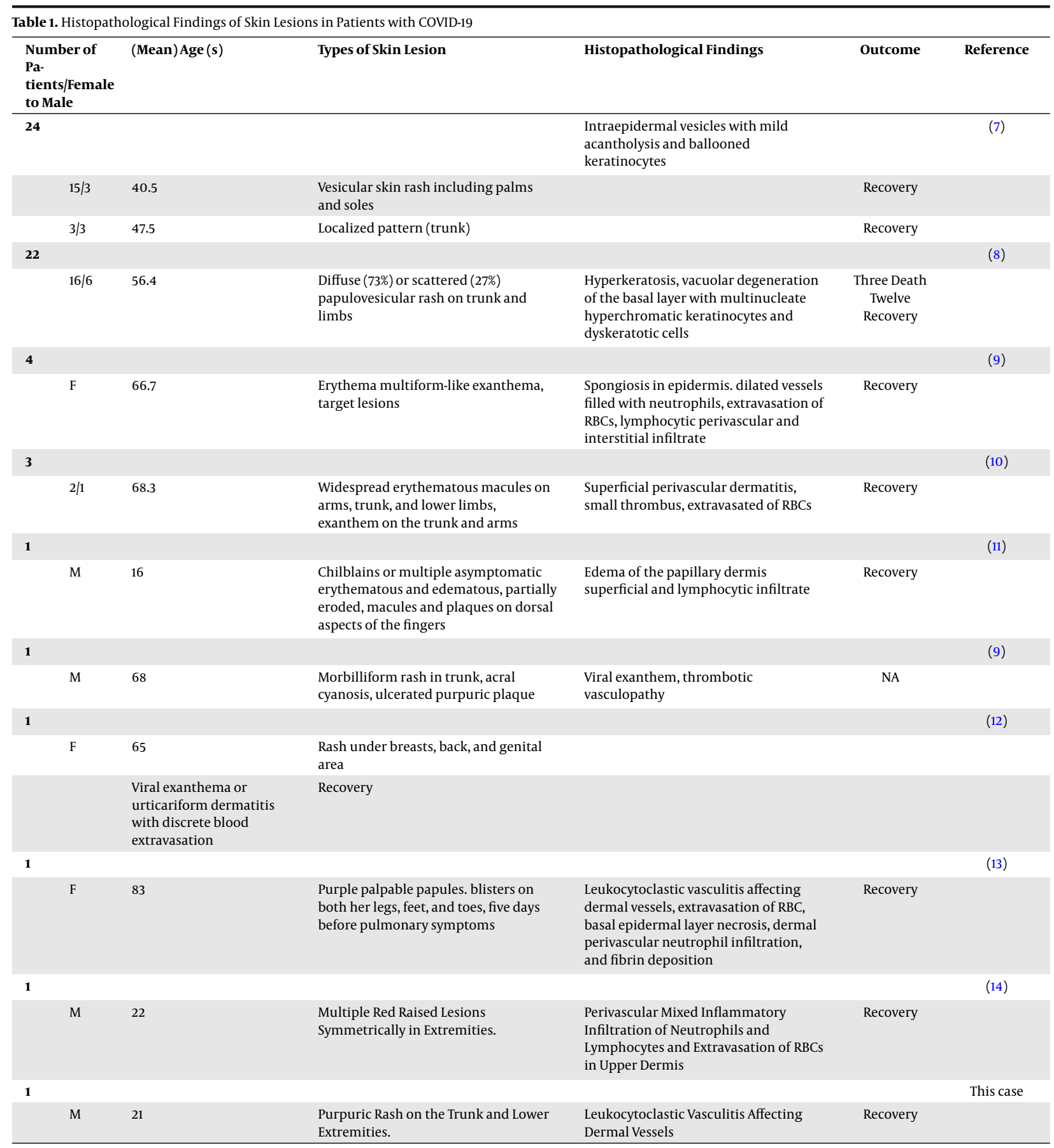

Conflict of Interests: The authors declare that they do not have any conflicts of interest.

Ethical Approval: IR.AJAUMS.REC.1399.018

Funding/Support: AJA University of Medical Sciences.

Informed Consent: We obtained informed consent from the patient for the publication of his illness course.

\section{References}

1. Worlmeter. Coronavirus worldwide graphs. USA:Worlmeter; 2021. Available from: https://www.worldometers.info/coronavirus/worldwidegraphs/.

2. Sala S, Peretto G, Gramegna M, Palmisano A, Villatore A, Vignale $\mathrm{D}$, et al. Acute myocarditis presenting as a reverse Tako-Tsubo 
syndrome in a patient with SARS-CoV-2 respiratory infection. Eur Heart J. 2020;41(19):1861-2. doi: 10.1093/eurheartj/ehaa286. [PubMed: 32267502]. [PubMed Central: PMC7184339].

3. Toscano G, Palmerini F, Ravaglia S, Ruiz L, Invernizzi P, Cuzzoni MG, et al. Guillain-Barre syndrome associated with SARS-CoV-2. N EnglJMed.2020;382(26):2574-6. doi: 10.1056/NEJMc2009191. [PubMed: 32302082]. [PubMed Central: PMC7182017].

4. Ellul MA, Benjamin L, Singh B, Lant S, Michael BD, Easton A, et al. Neurological associations of COVID-19. Lancet Neurol. 2020;19(9):767-83. doi: 10.1016/s1474-4422(20)30221-0.

5. Mangalmurti N, Hunter CA. Cytokine storms: Understanding COVID19. Immunity. 2020;53(1):19-25. doi: 10.1016/j.immuni.2020.06.017. [PubMed: 32610079]. [PubMed Central: PMC7321048].

6. Saulsbury FT. Henoch-Schonlein purpura. Curr Opin Rheumatol. 2001;13(1):35-40. doi: 10.1097/00002281-200101000-00006. [PubMed: 11148713].

7. Fernandez-Nieto D, Ortega-Quijano D, Jimenez-Cauhe J, Burgos-Blasco P, de Perosanz-Lobo D, Suarez-Valle A, et al. Clinical and histological characterization of vesicular COVID-19 rashes: A prospective study in a tertiary care hospital. Clin Exp Dermatol. 2020;45(7):872-5. doi: 10.1111/ced.14277. [PubMed: 32384180]. [PubMed Central: PMC7273083].

8. Marzano AV, Genovese G, Fabbrocini G, Pigatto P, Monfrecola G, Piraccini BM, et al. Varicella-like exanthem as a specific COVID-19associated skin manifestation: Multicenter case series of 22 patients. J Am Acad Dermatol. 2020;83(1):280-5. doi: 10.1016/j.jaad.2020.04.044. [PubMed: 32305439]. [PubMed Central: PMC7161488].

9. Jimenez-Cauhe J, Ortega-Quijano D, Carretero-Barrio I, Suarez-Valle A, Saceda-Corralo D, Moreno-Garcia Del Real C, et al. Erythema multiforme-like eruption in patients with COVID-19 infection: Clinical and histological findings. Clin Exp Dermatol. 2020;45(7):892-5. doi: 10.1111/ced.14281. [PubMed: 32385858]. [PubMed Central: PMC7272969].

10. Gianotti R, Veraldi S, Recalcati S, Cusini M, Ghislanzoni M, Boggio $\mathrm{F}$, et al. Cutaneous clinico-pathological findings in three COVID-19positive patients observed in the metropolitan area of Milan, Italy. Acta Derm Venereol. 2020;100(8):adv00124. doi: 10.2340/000155553490. [PubMed: 32315073].

11. Locatelli AG, Robustelli Test E, Vezzoli P, Carugno A, Moggio E, Consonni L, et al. Histologic features of long-lasting chilblainlike lesions in a paediatric COVID-19 patient. J Eur Acad Dermatol Venereol.2020;34(8):e365-8. doi: 10.1111/jdv.16617. [PubMed: 32386459]. [PubMed Central: PMC7273022].

12. Martin Carreras-Presas C, Amaro Sanchez J, Lopez-Sanchez AF, JaneSalas E, Somacarrera Perez ML. Oral vesiculobullous lesions associated with SARS-CoV-2 infection. Oral Dis. 2021;27(Suppl 3):710-2. doi: 10.1111/odi.13382. [PubMed: 32369674]. [PubMed Central: PMC7267423].

13. Mayor-Ibarguren A, Feito-Rodriguez M, Quintana Castanedo L, RuizBravo E, Montero Vega D, Herranz-Pinto P. Cutaneous small vessel vasculitis secondary to COVID-19 infection: A case report. J Eur Acad Dermatol Venereol. 2020;34(10):e541-2. doi: 10.1111/jdv.16670. [PubMed: 32441876]. [PubMed Central: PMC7280661].

14. Sandhu S, Chand S, Bhatnagar A, Dabas R, Bhat S, Kumar H, et al. Possible association between IgA vasculitis and COVID-19. Dermatol Ther. 2021;34(1). e14551. doi: 10.1111/dth.14551. [PubMed: 33200863]. [PubMed Central: PMC7744895]. 